\title{
ANÁLISE TÉCNICA E ECONÔMICA DO FORWARDER EM TRÊS SUBSISTEMAS DE COLHEITA DE FLORESTAS DE EUCALIPTO ${ }^{1}$
}

\author{
Luciano José Minette 2 , Fábio Murilo Tieghi Moreira ${ }^{3}$, Amaury Paulo de Souza ${ }^{4}$, Carlos Cardoso Machado ${ }^{4}$ e \\ Kátia Regina Silva ${ }^{3}$
}

\begin{abstract}
RESUMO - O objetivo deste trabalho foi avaliar técnica e economicamente o forwarder em três subsistemas de colheita em florestas de eucalipto. A análise técnica englobou um estudo de tempos e movimentos e de produtividade. A análise econômica englobou os parâmetros custo operacional, custo de produção e rendimento energético. O elemento carregamento abrangeu mais de $80 \%$ do tempo total, em todos os subsistemas. Os tempos dos elementos viagem vazio e viagem carregado foram influenciados principalmente pela distância média a ser percorrida. Chegou-se ao custo operacional de US $\$ 60,70 /$ he. Os custos de produção do forwarder foram de 1,74, 1,53 e 2,51 US $\$ / \mathrm{m}^{3} \mathrm{cc}$, nos subsistemas 1, 2 e 3, respectivamente; e o rendimento energético foi de 2,76, 2,42 e $3,98 \mathrm{~g} / \mathrm{kW}^{*} \mathrm{~m}^{3} \mathrm{cc}$, nos subsistemas 1,2 e 3 , respectivamente.
\end{abstract}

Palavras-chave: Colheita florestal, custo e mecanização florestal.

\section{TECHNICAL AND ECONOMIC ANALYSIS OF A FORWARDER UNDER THREE EUCALYPTUS FOREST HARVEST SUBSYSTEMS}

\begin{abstract}
This work aimed to evaluate a forwarder, technically and economically, under three eucalyptus forest harvest subsystems. The technical analysis included a productivity and motion and time study. The economic analysis included the parameters operational cost, production cost and energy consumption. Loading consumed more than $80 \%$ of the total cycle time in the subsystems studied. The average travel distance influenced unloaded and loaded travel times. The forwarder's operational cost was US \$ 60.70/ha. The forwarder production costs were US\$ $1.74,1.53$ and $2.51 / \mathrm{m}^{3} \mathrm{cc}$, in subsystems 1,2 and 3, respectively. The energy consumption rates were 2.76; 2.42 and $3.98 \mathrm{~g} / \mathrm{kW}^{*} \mathrm{~m}^{3} \mathrm{cc}$, (FORMATAR ) in subsystems 1, 2 and 3, respectively.
\end{abstract}

Key words: Timber harvesting, logging cost and forest mechanization.

\section{INTRODUÇÃO}

No setor florestal, a colheita de madeira é a fase mais importante do ponto de vista econômico, dada à sua alta participação no custo final do produto e aos riscos de perda envolvidos nessa atividade (Duarte, 1994). De acordo com Machado (1989), a exploração e o transporte representam 50\%, ou mais, do total dos custos finais da madeira posta na indústria.
Portanto, faz-se necessária e urgente a procura de técnicas que tornem a colheita e o beneficiamento da madeira mais racionais, visando o maior aproveitamento do material lenhoso (Jacovine et al., 2001). Dentre essas novas técnicas, a mecanização das atividades de colheita vem ganhando destaque nos últimos anos, por proporcionar vantagens em relação aos métodos utilizados até o momento (Moreira, 1998). Entre as máquinas mais utilizadas na exploração florestal estão

1 Recebido para publicação em 13.2.2003 e aceito para publicação em 17.2.2004.

Trabalho desenvolvido com recursos financeiros do CNPq.

2 Pesquisador Titular do Dep. de Engenharia Florestal da Universidade Federal de Viçosa - UFV, 36570-000 Viçosa-MG; ${ }^{3}$ Estudante D.S., do Dep. de Engenharia Florestal da UFV; ${ }^{4}$ Professor Titular do Dep. de Engenharia Florestal da UFV. 
os forwarders, que são tratores florestais cuja função é realizar a extração de madeira. A forma de extração é o transporte primário (autocarregamento). O sistema rodante pode ser de pneus ou de esteiras. Segundo Santos (1995), o forwarder apresenta o tempo de carga como o elemento que consome a maior parte do ciclo operacional. Sua produtividade cresce à medida que o volume por árvores aumenta e a distância de extração diminui, e decresce na situação inversa.

O objetivo deste trabalho foi avaliar técnica e economicamente o desempenho do forwarder em três subsistemas de colheita em florestas de eucalipto.

\section{MATERIAL E MÉTODOS}

\subsection{Região de Estudo}

O trabalho foi conduzido em povoamentos de eucalipto de uma empresa do setor, situados na região noroeste do Estado de São Paulo, entre os paralelos $22^{\circ} 55^{\prime}$ de latitude sul e $48^{\circ} 50^{\prime}$ de longitude oeste e a $750 \mathrm{~m}$ de altitude. $\mathrm{O}$ tipo de solo predominante na região é o Latossolo Vermelho-Escuro (LE), e o relevo é plano a suave-ondulado. O clima característico da região é o Cwa, clima quente úmido, de inverno seco, conforme a classificação de Köppen. A precipitação média anual é de aproximadamente $1.200 \mathrm{~mm}$, a temperatura média anual situa-se em torno de $21{ }^{\circ} \mathrm{C}$ e a umidade relativa média do ar é de $60 \%$. O reflorestamento da empresa na região era constituído da espécie E. grandis, em regime de segunda talhadia.

\subsection{Descrição do Forwarder}

O forwarder analisado neste trabalho era da marca Timberjack, modelo 1210B, com tração $6 \times 6$, motor Perkins 1006, com potência nominal de 172 hp; sistema rodante com pneus $700 \times$ x 26,5-16; grua modelo Loglift, com alcance de 7,2 $\mathrm{m}$; garra com capacidade de $0,35 \mathrm{~m}^{2}$; e capacidade de carga de $12 \mathrm{t}$ (Figura 1).

\subsection{Subsistemas de Colheita}

Os subsistemas avaliados foram:

Subsistema 1 - A derrubada foi realizada com o feller-buncher. Ele derrubou cada um dos dois eitos de trabalho, todos em um único sentido, com a base dos feixes direcionada para a extremidade do talhão onde se iniciava a derrubada; os feixes eram direcionados a aproximadamente $30^{\circ}$ em relação ao alinhamento do plantio. Em seguida, realizou-se o processamento da madeira dentro do talhão, pelo slingshot. A movimentação da máquina foi feita de acordo com o sentido de deslocamento do feller-buncher; iniciando o processamento pela extremidade do talhão onde o fellerbuncher finalizou a derrubada do eito. A etapa final deste subsistema consistiu na extração realizada com o forwarder, que se deslocava sobre a mesma linha de tráfego do slingshot, extraindo cada eito de trabalho isoladamente, ou seja, realizando o carregamento apenas por um lado, pelo fato de a distância entre as pilhas de cada eito ser maior que o alcance máximo da grua do forwarder. Metade do comprimento de cada eito de trabalho foi extraída para cada extremidade do talhão, visando otimizar a distância média de extração.
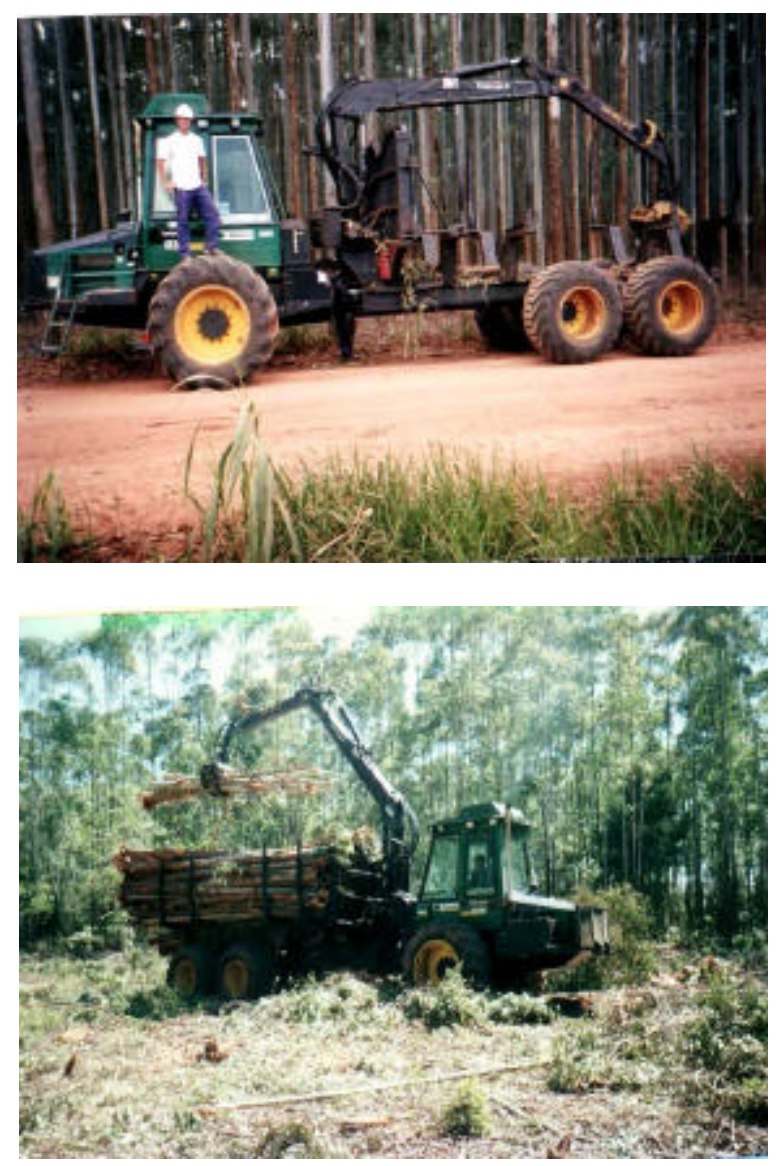

Figura 1 - Forwarder estudado neste trabalho. Figure 1 - Forwarder studied in this work. 
Subsistema 2 - A etapa completa de corte (derrubada e processamento) foi realizada pelo slingshot, sendo a faixa de corte de quatro linhas. O slingshot desloca-se sobre a segunda linha, realizando a derrubada da primeira linha por um lado e da terceira e quarta por outro, sendo as pilhas formadas após o processamento posicionadas entre a terceira e a quarta linhas de corte. A etapa final foi a extração da madeira com o forwarder, sendo o procedimento operacional similar ao descrito para o subsistema 1. Porém, neste caso, o fato de a distância entre as pilhas formadas nos eitos de trabalho ser menor proporcionava condições para que o carregamento fosse realizado por ambos os lados (direito e esquerdo).

Subsistema 3 - No subsistema 3, a etapa completa de corte (derrubada + processamento) foi realizada de forma semimecanizada, com o uso da motosserra e do machado. A equipe era constituída de um operador de motosserra e um ajudante, trabalhando em sistema de revezamento. A faixa de corte utilizada foi a de cinco linhas.

A etapa seguinte foi a extração realizada com o forwarder, que tinha três faixas de extração, nos dois eitos de corte utilizados em cada parcela. Na primeira faixa, o forwarder deslocava-se sobre a primeira linha de corte de eito, carregando, por um lado, a madeira proveniente da primeira, segunda, terceira e quarta linhas de um eito de corte e, por outro, a madeira proveniente da quarta e quinta linhas do outro eito. Na segunda faixa de extração, o forwarder deslocava-se sobre a quinta linha de um eito de corte, baldeando apenas a madeira proveniente desta linha, e por fim, na terceira faixa de extração, oforwarder deslocava-se sobre a primeira linha do outro eito de corte, baldeando por um único lado a madeira proveniente da primeira, segunda e terceira linhas daquele eito. Em todos os sistemas o comprimento das toras era de $6 \mathrm{~m}$ e a mãode-obra utilizada foi toda própria.

\subsection{Coleta de Dados}

Em primeiro lugar, foi feito um estudo piloto dos subsistemas de colheita analisados, buscando definir o número de observações necessárias para proporcionar um erro de amostragem máximo de 5\%, segundo a metodologia proposta por BARNES (1968), por meio da seguinte expressão:

$$
n \geq \frac{t^{2}+C V^{2}}{E^{2}}
$$

em que $\mathrm{n}=$ número mínimo de ciclos necessários; $\mathrm{t}=$ valor de $\mathrm{t}$, para o nível de probabilidade desejado e (n-1) graus de liberdade; $\mathrm{CV}=$ coeficiente de variação, em porcentagem; e $\mathrm{E}=$ erro admissível, em porcentagem.

Sabendo-se o número de observações necessárias e levando em consideração as faixas de trabalho utilizadas pela empresa, definiu-se o tamanho da área a ser explorada por cada subsistema que proporcionasse o número mínimo de observações a serem coletadas. A partir desse ponto, foi selecionado um talhão que seria explorado na seqüência, sendo então alocadas três parcelas de 42 linhas de plantio cada uma. Depois de alocadas as parcelas no campo, fez-se o inventário de cada parcela. Paralelamente ao inventário realizou-se o censo de cada parcela, obtendo-se o número exato de árvores existentes. Com os resultados apresentados no Quadro 1, estratificou-se cada parcela, segundo o volume médio por árvore.

Quadro 1 - Características dendrométricas das parcelas experimentais

Table 1 - Dendrometric features of the experimental plots

\begin{tabular}{|c|c|c|c|c|c|c|}
\hline Parcela & $\begin{array}{c}\text { Área/ } \\
\text { Parcela } \\
(\text { ha })\end{array}$ & $\begin{array}{c}\text { DAP } \\
\text { Médio } \\
(\mathrm{cm})\end{array}$ & $\begin{array}{c}\text { Altura } \\
\text { Média } \\
(\mathrm{m})\end{array}$ & $\begin{array}{c}\text { Volume/ha } \\
\left(\mathrm{m}^{3} \mathrm{cc}\right)\end{array}$ & Árvores/ha & $\begin{array}{c}\text { Volume } \\
\text { Médio/Árvore } \\
\left(\mathrm{m}^{3} \mathrm{cc}\right)\end{array}$ \\
\hline $\mathrm{A}$ & 6,3 & 9,0 & 13,9 & 133,7 & 1375 & 0,054 \\
\hline $\mathrm{B}$ & 6,3 & 9,7 & 15,2 & 171,3 & 1431 & 0,068 \\
\hline $\mathrm{C}$ & 6,3 & 10,4 & 15,5 & 189,9 & 1469 & 0,079 \\
\hline
\end{tabular}

\subsection{Análise técnica}

A análise técnica do forwarder em cada subsistema estudado baseou-se nos seguintes parâmetros:

a) Estudo de tempo e movimentos: Utilizou-se o método de tempo parcial. No estudo foram utilizados um cronômetro sexagesimal, uma prancheta e formulários específicos, onde foram registrados os dados. Os tempos dos elementos do ciclo foram registrados na forma sexagesimal e, posteriormente, convertidos para a forma centesimal.

b) Produtividade: A produtividade do forwarder foi determinada em metros cúbicos com casca por hora efetiva de trabalho, para cada parcela, sendo a produtividade representativa de cada subsistema a média das três parcelas. 
Produtividade $=\frac{\text { número de árvores } \times \text { volume por árvore }}{\text { horas efetivamente trabalhadas }}$

em que número de árvores = obtido através de um censo completo realizado a priori em cada parcela experimental; volume por árvore = volume médio por árvore em cada parcela, obtido através do inventário da área; e horas efetivamente trabalhadas $=$ horas efetivas de trabalho gastas em cada parcela experimental, obtidas por meio do estudo de tempos e movimentos e da coleta das horas efetivas trabalhadas em cada subsistema.

\subsection{Análise Econômica}

A análise econômica do forwarder em cada subsistema analisado baseou-se nos seguintes parâmetros:

a) Custo operacional: Os custos operacionais do forwarder foram obtidos diretamente da planilha de custos da empresa onde foi realizado o trabalho, englobando:

custos fixos: depreciação, juros e seguros; e

custos variáveis: combustíveis, lubrificantes e graxas, óleo hidráulico, pneus, manutenção e reparos, transporte de pessoal e de maquinário e custos de pessoal operacional.

O custo operacional total foi obtido ao somar os custos fixos e os variáveis mais o custo de administração.

b) Custo de produção: O custo de produção foi obtido pela divisão dos custos operacionais (US\$/he) pela produtividade $\left(\mathrm{m}^{3} \mathrm{cc} / \mathrm{he}\right)$ do forwarder, dentro de cada subsistema estudado.

c) Rendimento energético: $O$ rendimento energético foi obtido pela razão entre o consumo específico de combustível $\left(\mathrm{g} / \mathrm{kW}^{*} \mathrm{he}\right)$ e a produtividade $\left(\mathrm{m}^{3} \mathrm{cc} / \mathrm{he}\right)$ do forwarder, dentro de cada subsistema estudado, tendo sido dado em $\mathrm{g} / \mathrm{kW}^{*} \mathrm{~m}^{3} \mathrm{cc}$.

\section{RESULTADOS E DISCUSSÃO}

\subsection{Estudo de Tempo e Movimentos}

A constituição média dos elementos do ciclo operacional do forwarder nos subsistemas analisados é mostrada na Figura 2. Estes valores correspondem a um ciclo operacional de extração com uma distância média de 122, 129 e 132 m, para os subsistemas 1, 2 e 3,
Subsistema 1

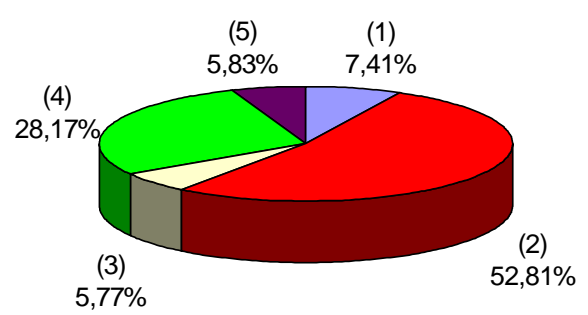

Subsistema 2

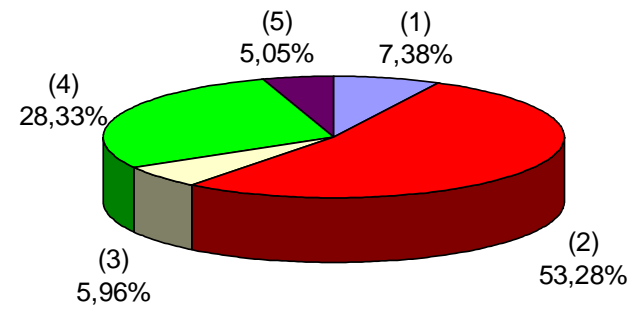

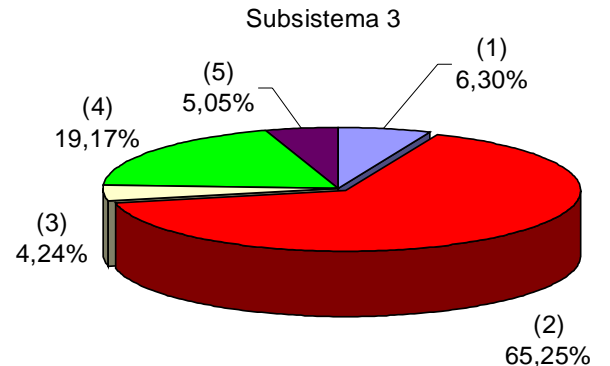

(1) - Viagem Vazio; (2) - Carregamento; (3) - Viagem Carregado; (4) - Descarregamento; e (5) - Interrupções.

Figura 2 - Composição porcentual do tempo total do ciclo operacional do forwarder nos subsistemas 1, 2 e 3.

Figure 2 - Percentile composition of the total time of the operational cycle of the forwarder in subsystems 1, 2 and 3.

R. Árvore, Viçosa-MG, v.28, n.1, p.91-97, 2004 
respectivamente. $\mathrm{O}$ ciclo operacional total do forwarder foi, em média, de 17,28; 16,00; e 24,62 minutos, nos subsistemas 1,2 e 3 , respectivamente.

Pode-se constatar que os elementos carregamento e descarregamento, juntos, corresponderam mais de $80 \%$ do tempo total do ciclo operacional do forwarder, em todos os subsistemas analisados. Os tempos dos elementos viagem vazio e viagem carregado foram influenciados principalmente pela distância média a ser percorrida. No Quadro 2 estão as equações que relacionam os tempos de viagem vazio e carregado com a distância. Os sinais positivos do coeficiente da variável distância em todos os modelos indicam que o aumento na distância média ocasionou aumento nos tempos das viagens vazio e carregado. As interrupções operacionais mais observadas foram: manobra para retorno ao talhão após a descarga, ajeitar carga na carreta, ajeitar a pilha formada na beira do talhão e limpar a estrada, retirando os galhos e as toras que caíam na formação das pilhas.

Quadro 2 - Equações estimadas para os tempos das viagens vazio e carregado do forwarder nos subsistemas 1 , 2 e 3

Table 2 - Equations estimated for the unloaded and loaded travel times of the forwarder in subsystems 1,2 and 3

\begin{tabular}{|c|c|c|c|}
\hline $\begin{array}{c}\text { Subsis- } \\
\text { tema }\end{array}$ & \multicolumn{1}{|c|}{ Equação } & $\mathrm{R}^{2}$ & $\mathrm{CV}(\%)$ \\
\hline \multirow{2}{*}{1} & $\mathrm{TVV}=0,0980^{*}+0,0081^{* *} \times$ Dist & 0,93 & 12,77 \\
\cline { 2 - 5 } & $\mathrm{TVC}=0,1705^{*}+0,0084^{* *} \times$ Dist & 0,93 & 15,53 \\
\hline \multirow{2}{*}{2} & $\mathrm{TVV}=-0,0572^{* * *}+0,0082^{* *} \times$ DDist & 0,95 & 11,64 \\
\cline { 2 - 5 } & $\mathrm{TVC}=0,0779^{*}+0,0082^{* *} \times$ xist & 0,93 & 16,93 \\
\hline \multirow{2}{*}{3} & $\mathrm{LnTVV}=-0,7692^{* *}+0,0063^{* *} \times$ Dist & 0,80 & 78,28 \\
\cline { 2 - 5 } & $\mathrm{TVC}=0,1997^{* *}+0,0087^{* *} \times$ Dist & 0,84 & 25,29 \\
\hline
\end{tabular}

TVV = tempo de viagem vazio $(\mathrm{min}) ; \mathrm{TVC}=$ tempo de viagem carregado $(\min ) ; \mathrm{R}^{2}=$ coeficiente de determinação; Dist = distância $(\mathrm{m})$; $\mathrm{CV}=$ coeficiente de variação; $* *$ significativo a $1 \%$ de probabilidade; $*=$ significativo a $5 \%$ de probabilidade; $\mathrm{e}^{* * *}=$ significativo a $15 \%$ de probabilidade.

No subsistema 2 o tempo total mostrou-se $8 \%$ menor que no subsistema 1, principalmente devido ao elemento carregamento. Essa diferença deveu-se ao menor número de deslocamentos durante o carregamento ocorrido neste subsistema, que foi em média de 3,78 , enquanto no subsistema 1 foi de 4,92. Esse fato ocorreu porque no subsistema 1, devido à distância entre as pilhas, o forwarder realizava o carregamento apenas por um lado, enquanto no outro realizava o carregamento por ambos os lados, sendo necessário, com isto, menor número de deslocamentos para completar a carga. O subsistema 3 mostrou um tempo total superior aos outros subsistemas, principalmente devido ao carregamento. No subsistema 3 a madeira foi apenas aproximada, formando feixes dispersos pela área devido ao método de corte, que era semimecanizado, sendo o empilhamento realizado manualmente, e, em razão do comprimento das toras, a movimentação destas era difícil. Com isto, o forwarder tinha que se deslocar mais vezes durante o carregamento para completar a carga, deslocando-se em média 7,82 vezes.

\subsection{Produtividade}

A produtividade apresentada pelo forwarder em metros cúbicos com casca por hora efetiva de trabalho foi de 35,47, 40,15 e 24,38, nos subsistemas 1, 2 e 3, respectivamente.

O forwarder, no subsistema 2, teve uma redução média no tempo total do ciclo de $8,00 \%$ em relação ao subsistema 1, o que acabou proporcionando rendimento, em termos de volume baldeado, $13,19 \%$ superior neste em relação ao subsistema 1 .

O subsistema 3 mostrou rendimento bem inferior aos outros subsistemas, cerca de 64,68 e 45,49\% menor que os subsistemas 2 e 1, respectivamente. Acredita-se que, com melhor planejamento da etapa de corte, assim como redução no comprimento das toras, o que facilitaria a movimentação e o arranjamento destas, o rendimento do forwarder neste subsistema poderia ter ganho expressivo.

\subsection{Custo Operacional}

Considerando-se uma taxa de juros de $12 \%$ a.a. e uma eficiência operacional de $80 \%$, chegou-se ao custo/ hora efetivamente trabalhada de US\$60,70. Os custos fixos, neste caso, corresponderam a aproximadamente $47,69 \%$ e os variáveis, a aproximadamente $51,01 \%$ dos custos totais, respectivamente; o custo de administração foi da ordem de 1,30\% dos custos totais (Figura 3).

\subsection{Custo de Produção e Rendimento Energético}

No Quadro 3 estão os custos de produção e o rendimento energético do forwarder nos três subsistemas

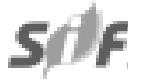

R. Árvore, Viçosa-MG, v.28, n.1, p.91-97, 2004 


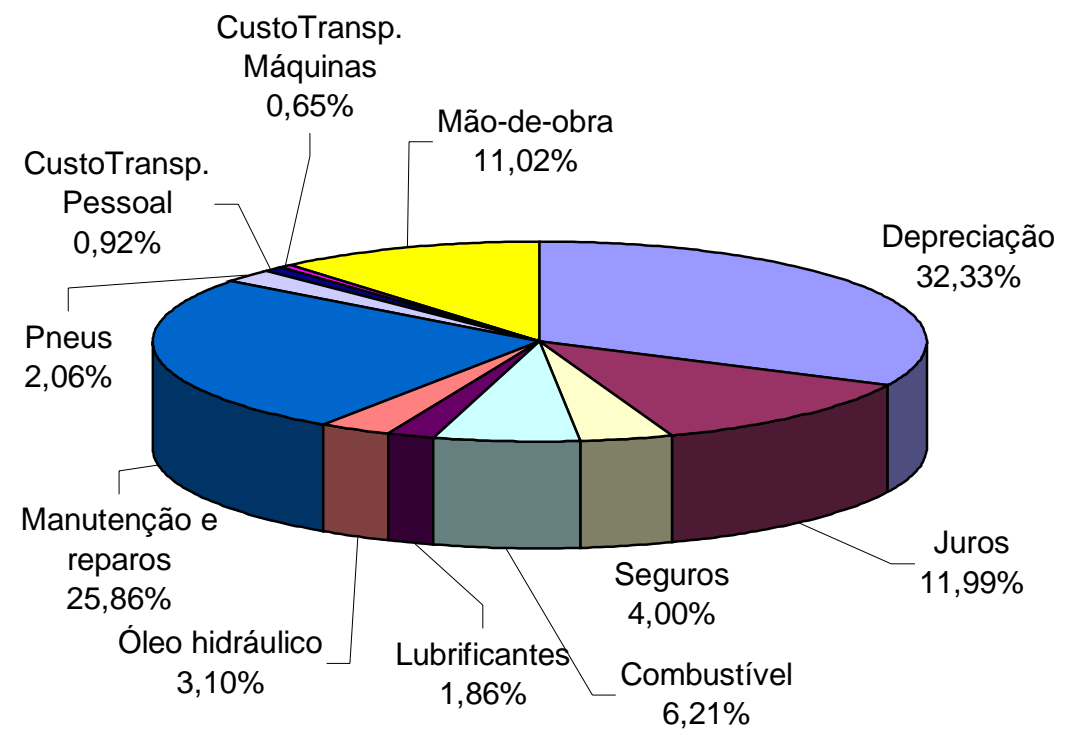

Figura 3 - Distribuição porcentual dos itens que compõem o custo operacional do forwarder.

Figure 3 - Percentile distribution of the items of the operational cost of the forwarder.

Quadro 3 - Custo de produção e rendimento energético do forwarder

Table 3 - Cost of production and energy consumption of the forwarder

\begin{tabular}{|c|c|c|}
\hline Subsistema & $\begin{array}{c}\text { Custo de Produção } \\
\left(\mathrm{US} \$ / \mathrm{m}^{3} \mathrm{cc}\right)\end{array}$ & $\begin{array}{c}\text { Rend.Energético } \\
\left(\mathrm{g} / \mathrm{kW}^{*} \mathrm{~m}^{3} \mathrm{cc}\right)\end{array}$ \\
\hline 1 & 1,74 & 2,76 \\
\hline 2 & 1,53 & 2,42 \\
\hline 3 & 2,51 & 3,98 \\
\hline
\end{tabular}

de colheita. Nota-se que o custo de produção e o rendimento energético no subsistema 2, em geral, foram menores que no subsistema 1 , em função de no subsistema 2 ser possível para o forwarder realizar o carregamento por ambos os lados, o que se traduziu em aumento no valor do seu rendimento e conseqüente redução no custo de produção e no valor do rendimento energético, em relação ao subsistema 1 .

O custo de produção e o rendimento energético do forwarder no subsistema 3 mostraram-se superiores aos dos subsistemas 1 e 2; esse maior custo de produção e pior rendimento energético deveram-se à baixa produtividade do forwarder neste subsistema em relação aos outros subsistemas em que ele atuou. Observou-se que o custo de produção decresceu à medida que se aumentou o volume médio por árvore, em todos os subsistemas analisados; essa tendência deveu-se ao aumento na produtividade do forwarder quando se aumentou o volume médio por árvore.

\section{CONCLUSÕES}

Com base na análise e discussão dos resultados, pode-se concluir:

- Os elementos carregamento e descarregamentos, juntos, corresponderam mais de $80 \%$ do tempo total do ciclo operacional do forwarder em todos os subsistemas analisados.

- Os tempos dos elementos viagem vazio e viagem carregado foram influenciados principalmente pela distância média a ser percorrida, tendo os sinais positivos do coeficiente da variável distância em todos os modelos indicado que o aumento na distância média ocasionou aumento nos tempos das viagens vazio e carregado.

- As interrupções operacionais mais observadas foram: manobrar para retorno ao talhão após a descarga, ajeitar carga na carreta, ajeitar a pilha formada na beira do talhão e limpar a estrada, retirando-se os galhos e toras que caíam na formação das pilhas. 
- O subsistema 3 mostrou um tempo total superior ao dos outros subsistemas, principalmente devido ao carregamento.

- A produtividade apresentada pelo forwarder em metros cúbicos com casca por hora efetiva de trabalho foi de $35,47,40,15$ e 24,38, nos subsistemas 1,2 e 3 , respectivamente.

- O subsistema 3 mostrou rendimento bem inferior aos outros subsistemas, cerca de 64,68 e $45,49 \%$ menor que os subsistemas 2 e 1 , respectivamente.

- Chegou-se ao custo operacional de US\$60,70 por hora efetivamente trabalhada.

- Os custos de produção do forwarder foram de 1,74, 1,53 e 2,51 US $\$ / \mathrm{m}^{3} \mathrm{cc}$, nos subsistemas 1,2 e 3 , respectivamente, e o rendimento energético foi de $2,76,2,42$ e $3,98 \mathrm{~g} / \mathrm{kW}^{*} \mathrm{~m}^{3} \mathrm{cc}$.

\section{REFERÊNCIAS BIBLIOGRÁFICAS}

BARNES, R. M. Motion and time study: design and measurement of work. 6.ed. New York: John Willey \& Sons, 1968. $799 \mathrm{p}$.
DUARTE, R. C. G. Sistemas de corte florestal mecanizado. 1994. $21 \mathrm{f}$. Monografia (Exigência para conclusão do curso de Engenharia Florestal) - Universidade Federal de Viçosa, Viçosa, 1994.

JACOVINE, L. A. G. et al. Avaliação da perda de madeira em cinco subsistemas de colheita florestal. Revista Árvore, v. 25 , n. 4 , p. 463-470, 2001.

MACHADO, C. C. Exploração florestal, 6. Viçosa: Universidade Federal de Viçosa, Imprensa Universitária, 1989. $34 \mathrm{p}$.

MOREIRA, F. M. T. Mecanização das atividades de colheita florestal. 1998. 25 f. Monografia (Exigência para conclusão do curso de Engenharia Florestal) - Universidade Federal de Viçosa, Viçosa, 1998.

SANTOS, S. L. M. Alocação ótima de máquinas na colheita de madeira. 1995. 99 f. Dissertação (Mestrado em Ciência Florestal) - Universidade Federal de Viçosa, Viçosa, 1995. 